\title{
Review
}

Blood Purif 2019;48:196-202

Received: January 8, 2019

DOI: $10.1159 / 000500013$

Accepted: March 29, 2019

Published online: April 30, 2019

\section{What Have We Learned about the Use of Cytosorb Adsorption Columns?}

\author{
Ghada Ankawi ${ }^{a, b}$ Yun Xie ${ }^{a, c}$ Bo Yang ${ }^{a, d}$ Yuanyuan Xie ${ }^{a, e}$ Pan Xie ${ }^{a, f}$ \\ Claudio Ronco ${ }^{\mathrm{a}, \mathrm{g}}$
}

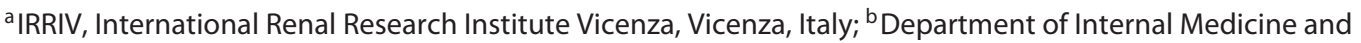
Nephrology, King Abdulaziz University, Jeddah, Saudi Arabia; 'Department of Nephrology Xin Hua Hospital Affiliated to Shanghai Jiaotong University School of Medicine, Shanghai, China; ${ }^{d}$ Department of Nephrology, First Teaching Hospital of Tianjin University of Traditional Chinese Medicine, Tianjin, China; ${ }^{e}$ Department of Nephrology, Molecular Cell Laboratory for Kidney Disease, Renji Hospital, School of Medicine, Shanghai Jiaotong University, Shanghai, PR China; ${ }^{\mathrm{f}}$ Department of Nephrology, Southwest Hospital, First Affiliated Hospital to TMMU, Third Military Medical University (Army Medical University), Chongqing, China; ${ }^{9}$ Department of Nephrology, Dialysis and Transplant, San Bortolo Hospital, Vicenza, Italy

\section{Keywords}

Extracorporeal therapy · Adsorption · Sepsis · Cardiac

surgery $\cdot$ Cytokines $\cdot$ Sorbents

\begin{abstract}
Extracorporeal blood purification techniques have emerged and evolved in the recent years as a potential therapy for the purpose of immunomodulation in acute conditions like sepsis. Understanding the extent of immune system dysregulation involved in the pathophysiology of these conditions, resulted in the development of such treatment strategies aiming at restoring a balanced inflammatory response. Beyond conventional continuous renal replacement therapy, high volume hemofiltration, high cut-off membranes, adsorption alone and coupled plasma filtration adsorption are well-described techniques in the literature. The evidence to support their routine use, however, is conflicting and insufficient at this stage. Despite the low-quality level of evidence in favor of utilizing these techniques, studies to further ex-
\end{abstract}

\section{KARGER}

(c) 2019 S. Karger AG, Basel

E-Mail karger@karger.com

www.karger.com/bpu plore their effectiveness, safety, and potential novel applications, continue to evolve. Our review aims at focusing on adsorption therapy, particularly using the adsorption columns Cystosorb.

(c) 2019 S. Karger AG, Basel

\section{Background}

The use of extracorporeal blood purification techniques for the purpose of immunomodulation in acute inflammatory states (such as sepsis, cardiac surgery, and autoimmune disease) has evolved in the recent years. Beyond conventional continuous renal replacement therapy, high volume hemofiltration, high cut-off membranes, adsorption alone, and coupled plasma filtration adsorption are well-described techniques in the literature. The evidence to support their use is conflicting at this stage; however, studies looking at effectiveness, safety, and potential novel applications continue to evolve [1]. Among 
the more rapidly evolving areas is adsorption therapy. Adsorption cartridges/columns with enhanced features continue to be developed. We here, aim to review, the published literature on the use of the adsorption columns Cystosorb (CS).

The CS device was approved in Europe in 2011 [2] and can actually be used as a stand-alone therapy or in combination with extracorporeal circuits, both in pre-dialyzer and post-dialyzer mode (Fig. 1).

CS is made up of biocompatible, highly porous, polyvinyl-pyrrolidone-coated polystyrene-divinyl-benzene polymer bead. Its estimated size is $300-800 \mu \mathrm{m}$ with a total surface area of more than $40,000 \mathrm{~m}^{2}$. The large surface area gives greater capacity for clearance than available dialyzers. Substances removal from whole blood is based on pore capture and surface adsorption. CS use is compatible with both systemic heparin and regional citrate anti-coagulation. The typical duration of therapy is up to $24 \mathrm{~h}$ per session, daily for 2-7 consecutive days. Blood flow is set in the range of $150-700 \mathrm{~mL} / \mathrm{min}$.

CS use is indicated in clinical conditions with cytokines elevation. It is effective in targeting middle-molecular-weight uremic and low-molecular-weight toxins with a wide range of molecular weights ( 5-60 $\mathrm{kDa}$ ). It however, does not capture endotoxins and interleukin (IL)-10, as generally adsorption is effective in pore size-dependent manner [3]. Of note, in an in vitro study testing the removal of a broad spectrum of toxic pathogen-associated molecular patterns and damageassociated molecular patterns [4], except for the tumor necrosis factor (TNF)- $\alpha$ trimer, hemoadsorption (HA) using CS reduced the levels of a broad spectrum of cytokines, damage-associated molecular patterns, pathogen-associated molecular patterns, and mycotoxins by $>50 \%$.

\section{Cytosorb Use in the Context of Sepsis}

Several cytokines along with their soluble receptors, in addition to chemokines, cell adhesion molecules have been implicated in the development of systemic inflammatory response syndrome and sepsis. These include TNF- $\alpha$, IL-1 $\beta$, IL-4, IL-6, IL-8, IL-10, IL-13, interferon- $\alpha$, and transforming growth factor- $\beta$. Elevated circulating concentrations of several cytokines, including TNF- $\alpha$, IL$1 \beta$, IL-6, IL- 8 , and IL-10 have been linked to morbidity and mortality in patients with sepsis. In response to the inflammatory mediators, anti-inflammatory cytokines, and cytokine antagonists are produced. The anti-inflam-

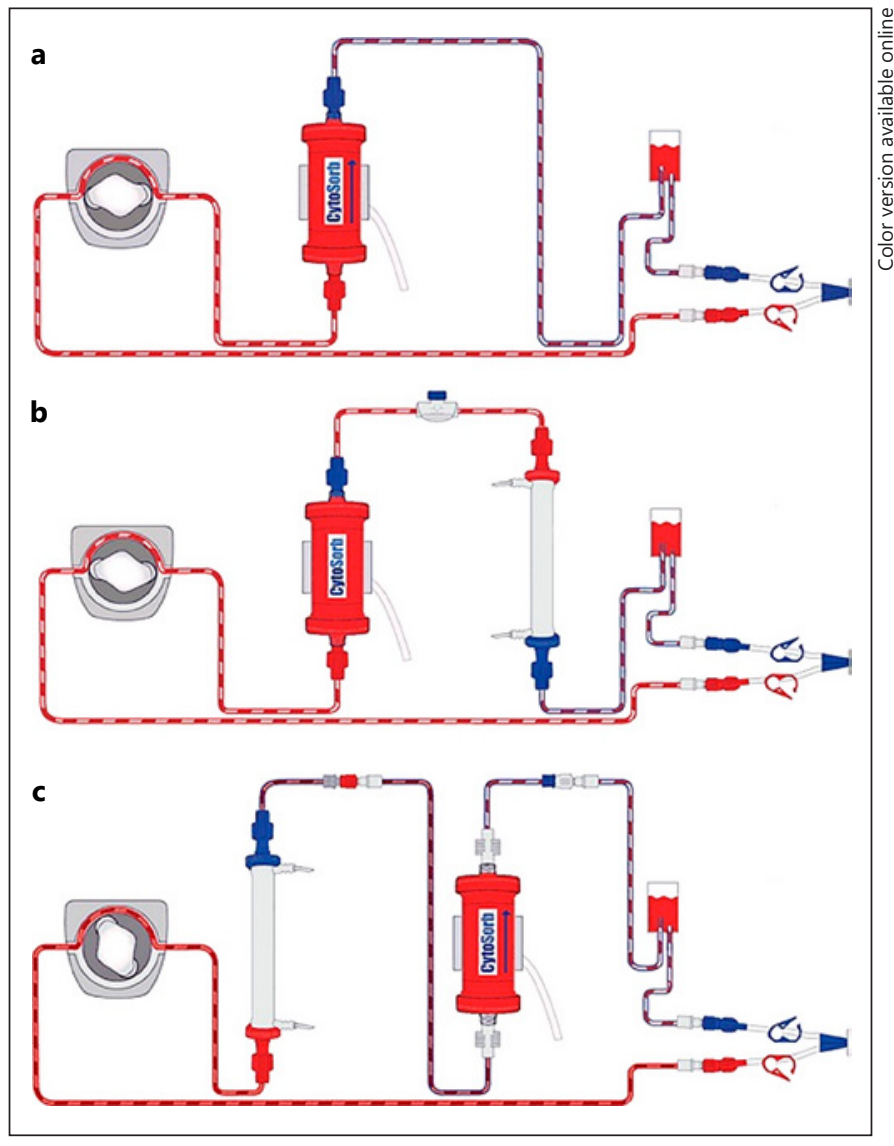

Fig. 1. CytoSorb circuit: (a) as a stand-alone therapy, (b) in the pre-dialyzer mode, $(\mathbf{c})$ in the post-dialyzer mode (Source: CytoSorbents Europe $\mathrm{GmbH}$ ).

matory cytokines IL-4, IL-10, and IL-13 inhibit the production of cytokines by native leukocytes.

The rational of utilizing adsorption therapy in the context of sepsis is to restore a balanced proinflammatory and anti-inflammatory mediators' response.

Observational data suggest improved hemodynamics and a trend toward improved mortality with the use of CS in septic patients. In the study by Friesecke et al. [5], 25 septic shock patients were treated with a single session of adsorption (pre-hemodialysis filter), and it was repeated as needed. This was associated with decreased vasopressors (compared to pre-hemoperfusion [HP]) and shock resolution in 13 of 20 cases (65\%). It was also associated with increased lactate clearance, and significant reduction in IL-6. No significant side effects were reported.

Furthermore, Kogelmann et al. [6] reported treatment of 16 septic shock patients with CS in addition to continuous veno-venous hemodialysis in the pre-filter mode (1-5 treatments). Treatment with CS was associated with 
Table 1. The main studies describing the use of Cytosorb in sepsis

\begin{tabular}{|c|c|c|c|c|}
\hline & Schädler et al. [7] 2013 & Friesecke et al. [5] 2017 & Schädler et al. [8] 2017 & Kogelmann et al. [6] 2017 \\
\hline Study design & RCT & Prospective interventional & RCT & Case series \\
\hline $\begin{array}{l}\text { IL-6 measurement, } \\
\mathrm{pg} / \mathrm{mL}\end{array}$ & - & $>1,000$ & Average of 565 & - \\
\hline Outcomes & $\begin{array}{l}28 \text {-day mortality } 28 \% \text { in the } \\
\text { treatment group vs. } 24 \% \text { in the } \\
\text { controls }(p=0.84)\end{array}$ & $\begin{array}{l}\text { Significant reduction in } \\
\text { VP requirements } \\
\text { compared to baseline }\end{array}$ & $\begin{array}{l}28 \text {-day mortality } 36.2 \% \text { in } \\
\text { the treatment group } \\
\text { vs. } 18.0 \% \text { in the controls } \\
(p=0.073)\end{array}$ & $\begin{array}{l}\text { The actual } 28 \text {-day, ICU and hospital } \\
\text { mortality was } 61.54,73.08 \text { and } 80.77 \% \text {, } \\
\text { respectively, compared with } 89.9 \% \text { as } \\
\text { predicted by APACHE II score }\end{array}$ \\
\hline Change in IL-6 & Significant reduction in IL-6 & $\begin{array}{l}\text { Significant reduction } \\
\text { in IL-6 }\end{array}$ & $\begin{array}{l}\text { IL- } 6 \text { reduction in the } \\
\text { HP group compared } \\
\text { with no HP }\end{array}$ & - \\
\hline Adverse events & $\begin{array}{l}\text { Modest reduction in platelet } \\
\text { count }(<10 \%) \text { and albumin }(<5 \%)\end{array}$ & No AE & $\begin{array}{l}1 \text { drop in platelets in the } \\
\text { treatment group }\end{array}$ & No AE \\
\hline
\end{tabular}

RCT, randomized controlled trial; ALI, acute lung injury; ARDS, acute respiratory distress syndrome; IL-6, interleukin-6; ICU, intensive care unit; AE, adverse events; ST, standard therapy; HP, hemoperfusion; RRT, renal replacement therapy; APACHE II, acute physiology and chronic health evaluation II; VP, vasopressors.

decreased 28-day, intensive care unit (ICU) and hospital mortality compared to predicted mortality by Acute Physiology and Chronic Health Evaluation II score in the overall patient population, $(61.54,73.08$, and $80.77 \%$, respectively, vs. $89.9 \%)$. It was also associated with decreased vasopressors (compared to pre-HP) in the survivors. Similar to previous studies, there were no significant side effects.

As far as randomized controlled trials, Schädler et al. [7], evaluated 43 septic shock patients with acute lung injury. Patients were randomized to standard of care versus standard of care plus HP. There was significant reduction in the inflammatory mediators in the intervention group compared to controls IL-6 $(-49.1 \%, p=0.01)$, monocyte chemotactic proteins-1 $(-49.5 \%, p=0.002)$, IL-1ra $(-36.5 \%, p=0.001)$, IL-8 $(-30.2 \%, p=0.002)$. However, this was not associated with improvement in survival (28-day mortality 28 vs. $24 \%$ control, $p=0.84$ and 60 -day mortality 39 vs. $32 \%$ control, $p=0.75$ ). Apart from modest reduction in platelet count $(<10 \%)$ and al- bumin $(<5 \%)$, there were no reported side effects [7]. In a later randomized controlled trial by the same authors [8], this time involving 97 septic shock patients with acute lung injury or acute respiratory distress syndrome, HP (in addition to renal replacement therapy [RRT] when indicated) was compared to no HP. There was significant reduction in IL-6 (5-18\% per pass of blood through the device) compared to no reduction in the standard of care group. Similar to their previous study, there was no reduction in the 28-day-mortality in the treatment group, and in fact, it was higher than the controls ( 36.2 vs. $18.0 \%, p=0.073$ ). There was also a higher 60 -day-mortality in the treatment group ( 44.7 vs. $26.0 \%$; $p=0.039$ ). Important to note, RRT requirement was higher in the treatment group (38.9 vs. 17.9\%), which may reflect a sicker population in this group, and hence the higher mortality. Overall, the study was not powered to examine mortality. Finally, CS use was not associated with significant side effects. Studies describing the use of CS in sepsis are summarized in Table 1. 
Table 2. The main studies describing the use of Cytosorb in cardiac surgery

\begin{tabular}{lllll}
\hline & Träger et al. [9] 2016 & Bernardi et al. [10] 2016 & Träger et al. [11] 2017 & Calabrò et al. [12] 2018 \\
\hline Study design & Retrospective case series & RCT & Retrospective case series & Retrospective case series \\
\hline Population, $n$ & $\begin{array}{l}\text { 16 patients with severe } \\
\text { post-CPB SIRS, and AKI }\end{array}$ & $\begin{array}{l}\text { 37 blinded patients } \\
\text { undergoing elective CPB } \\
\text { surgery (HP group 19 } \\
\text { vs. control group 18) }\end{array}$ & $\begin{array}{l}\text { 39 patients with IE } \\
\text { undergoing CS with HP vs. } \\
\text { 28 historical patients with } \\
\text { IE undergoing CPB with no HP }\end{array}$ & $\begin{array}{l}\text { 40 cardiac surgery ICU patients } \\
\text { with MOF }\end{array}$ \\
\hline Dose & $\begin{array}{l}\text { CS in combination with } \\
\text { CRRT }\end{array}$ & $\begin{array}{l}\text { Average duration } \\
191 \pm 56 \text { min }\end{array}$ & $\begin{array}{l}\text { Average duration 64-445 } \\
\text { (median 132) minutes }\end{array}$ & $\begin{array}{l}\text { At least one CS treatment } \\
\text { Average length of treatment }=3 \text { day } \\
\text { Median number of filters }=2\end{array}$ \\
\hline Outcomes & $\begin{array}{l}\text { Reduction in IL-6 and } \\
\text { IL-8 compared to baseline }\end{array}$ & $\begin{array}{l}\text { No differences in: } \\
\text { IL-6 level }\end{array}$ & Reduction in cytokines & $\begin{array}{l}\text { Reduction in 30-day mortality 55\% } \\
\text { and ICU mortality 52.5\% vs. } \\
\text { expected ICU mortality of 80\% }\end{array}$ \\
& $\begin{array}{l}\text { Improvement of } \\
\text { hemodynamics }\end{array}$ & VP requirement & Improvement of hemodynamics & Reduction in VP requirement \\
& $\begin{array}{l}\text { Reduction in VP } \\
\text { requirement }\end{array}$ & 30 -day mortality & &
\end{tabular}

$\mathrm{CPB}$, cardiopulmonary bypass; SIRS, systemic inflammatory response syndrome; AKI, acute kidney injury; CS, cytosorb; RCT, randomized controlled trial; IL-6, interleukin-6; IL-8, interleukin-8; IE, infective endocarditis; ICU, intensive care unit; MOF, multi-organ failure; HP, hemoperfusion; CRRT, continuous renal replacement therapy; VP, vasopressors.

\section{Cytosorb Use in the Contexts of Cardiac Surgery}

In contrast to the studies evaluating CS therapy in patients with sepsis, studies looking at CS use in cardiac surgery patients showed inconsistent results. A retrospective case series by Träger et al. [9], involved 16 patients with severe post-cardiopulmonary bypass (CPB) systemic inflammatory response syndrome, and acute kidney injury. CS in combination with continuous RRT resulted in a considerable reduction in IL-6 and IL-8 compared to baseline, paralleled by improved hemodynamic stability, and a reduction in vasopressor requirement.

On the other hand, in the study by Bernardi et al. [10], the use of CS in 37 blinded patients undergoing elective CPB surgery (19 patients in the HA group versus 18 patients in the control group), did not result in reduction of the pro-inflammatory response or changes in the perioperative course. The modest elevation of cytokines level in the setting of elective surgery in comparison to the much higher levels in active infection/sepsis may explain the discrepancy between the results of this study and prior reports. Another caveat is treatment duration, (average $191 \pm 56 \mathrm{~min}$, compared to treatment lasting for up to 7 days in other studies). This emphasizes the importance of both, initial level of cytokines, and treatment frequency/duration on the extent of cytokines reduction.
The potential improved effectiveness of CS therapy when initial cytokines levels are significantly elevated was supported by the study of Träger et al. [11]. In this study, 39 cardiac surgery patients with infective endocarditis (hence significantly elevated level of cytokines) undergoing valve replacement plus intraoperative HA were compared to 28 historical patients with infective endocarditis undergoing $\mathrm{CPB}$ with no HA. Treatment with CS was in fact associated with cytokines reduction and improved hemodynamic stability.

In a more recent retrospective case series by Calabrò et al. [12], involving 40 cardiac surgery ICU patients with multiple organ failure mainly due to cardiogenic shock (28/40), patients received at least one CS treatment. The average length of treatment was 3 days, with a median number of filters used of 2 . In this cohort, 30 day mortality was $55 \%$ and ICU mortality was $52.5 \%$ as compared to an expected ICU mortality of $80 \%$. There was significant reduction of the vasoactive inotropic score after $48 \mathrm{~h}$ of treatment as compared to baseline (20 vs. $10, p=0.009$ ). Furthermore, CS treatment was effective in reducing bilirubin, lactate, and lactate dehydrogenase. No device-related adverse events were observed. Studies describing the use of CS in cardiac surgery are summarized in Table 2. 


\section{Cytosorb Use in the Context of Organ Transplant}

In the study by Nemeth et al. [13], 84 orthotopic heart transplantation patients were separated into HA group or controls. Intraoperative HA treatment was associated with reduced vasopressor demand and less frequent RRT.

Furthermore, Kellum et al. [14] examined the possible role of CS therapy in the reduction of organ dysfunction (resulting from elevated inflammatory cytokines) in brain-dead potential transplant donors. Four hours of CS therapy was applied to potential donors, with measurement of pre/post treatment cytokines levels. Removal was significant for IL-6, 28\% ( $p=0.006)$, less significant for TNF, $8.5 \%$ ( $p=0.13)$, but not for IL-10. It was a feasibility study that showed a potential role, for CS therapy for this purpose. Although TNF and IL-6 increased after the first hour (indicating ongoing production), the rate of increase in both cytokines was less than expected [14].

\section{Cytosorb Use in Other Contexts}

Another potential application is the reduction of bile acids in liver failure patients. This was tested in an in vitro setting, and adsorption-based techniques (including CS) were more effective than high flux dialysis in the removal of hydrophilic bile acids [15].

Drug removal is another area where HP using CS was found to be effective. As an example, CS has been shown to be effective in the removal of rivaroxaban in an in vitro study. Within $1 \mathrm{~h}$ of HP using CS, $91.6 \%$ of the rivaroxaban from citrate-anticoagulated human whole blood was removed. The same recirculation system without a CS column showed only minor depletion over a test period of $5 \mathrm{~h} \mathrm{[16].} \mathrm{Another} \mathrm{example} \mathrm{is} \mathrm{tricagrelor.}$ CS was tested in the removal of tricagrelor from both bovine serum albumin and human blood. CS showed an excellent capacity of sorbents to bind and remove ticagrelor ( $>99 \%$ in plasma and whole blood as well as bovine serum albumin) [17]. There was minor drop in albumin $(<10 \%)$. Furthermore, in bench experiments, CS has also been shown to absorb up to $96 \%$ of radiocontrast [18].

It should be noted that drug removal is considered both, a potential therapeutic application (as in the case of overdose) and also a potential side effect of therapy. The possible removal of antibiotics, for example, in the case of sepsis, should be carefully monitored for and antibiotics doses may need to be adjusted. This was demonstrated in an in vitro study examining the removal of wide range of medications (including antibiotics) [19]. Uremic blood spiked with a range of therapeutic drugs was recirculated for $2 \mathrm{~h}$ in an in vitro HP circuit containing a Betasorb device for HP. The drug concentrations before and after the passage through the cartridge were measured and the total amount removed was calculated. The sorbent material showed effective removal of antibiotics (including vancomycin, amikacin, tobramycin, gentamicin), digoxin, theophylline, phenobarbital, phenytoin, carbamazepine, and valproic acid. Furthermore, it demonstrated moderate removal of tacrolimus and cyclosporine. Aminoglycosides were on the other hand removed to a small extent only. Overall, adsorption therapy represents a promising strategy in cases of overdose/intoxication. On the other hand, drug level monitoring should be performed when utilizing this technique for other clinical purposes. Medication doses may need to be adjusted to account for undesired losses.

\section{Where Do We Stand?}

The body of evidence to support the safety and effectiveness of CS continues to grow. A clinical registry on the use of CS involving 22 countries has been developed [20] and according to its most recent report, the use of CS in 135 septic patients was not associated with side effects. The observed mortality was $65 \%$ compared to a predicted risk of death of $78 \%$ based on the Acute Physiology and Chronic Health Evaluation II score. Marked reduction in IL-6 levels was also observed. Similarly, 17 CPB surgery patients had lower observed mortality (29\%) compared to predicted mortality (31\%).

\section{Conclusions}

Sorbents offer clear advantages compared to other extracorporeal techniques - first, the capacity for removal of a wide range of molecular weights and second, enhanced clearance due to large surface area of sorbents material. Third, sorbents do not rely on the removal of fluid for the clearance of toxins, potentially avoiding the time limitations of dialysis and the replacement fluid requirements of hemodiafiltration [21]. There are important caveats when considering using this technique: first, the proportionate relationship between the initial level of the target molecule for removal and the degree of clearance (higher initial levels result in better clearance); second, 
the role of frequent therapy, to account for possible ongoing production/rebound; lastly, the importance of drug level monitoring to account for possible undesired losses. Thus, adsorption therapy may be of utmost benefit when, applied early in the course, for an adequate duration, and frequently repeated until hemodynamic stability is achieved. As highlighted above, among the important potential side effects associated with the use of sorbents in general, including CS columns, is the removal of antibiotics, and other beneficial molecules. As such, patients undergoing adsorption therapy should be carefully monitored with drug levels (when possible), and supplemented with additional doses as needed. Furthermore, adsorption therapy has been associated with thrombocytopenia and leukopenia (as highlighted in the above described studies), that is typically mild and transient; however, close monitoring is essential.

We agree with the general consensus, that the evidence to support the use of extracorporeal blood purification techniques (in general) in sepsis/other acute conditions is insufficient at this point. However, the potential benefits of adsorption therapy (control of the exaggerated immune response in particular, which typically translates into hemodynamic stability) cannot be ignored. We often think of this type of therapy as a bridge to stabilize critically ill patients, until more definitive therapies take place. The availability of adsorption devices with different removal capacities as demonstrated in the in vitro study by Malard et al. [22] could enable treatment to be more tailored to patients' conditions resulting in better response.

Overall, adsorption therapy using CS columns seems to be safe and effective. Further studies to expand our knowledge on novel indications, such as management of the cytokine release syndrome, which complicates adoptive immunotherapies such as chimeric antigen receptor T cells [23] are warranted. Furthermore, criteria to start therapy and judge response needs to be better defined.

\section{Acknowledgments}

Not applicable.

\section{Statements of Ethics}

The authors have no ethical conflicts to disclose.

\section{Disclosure Statement}

The authors declare that they have no conflicts of interest to disclose.

\section{Funding Sources}

Not applicable.

\section{Author Contribution}

G.A.: carried out the literature review, manuscript drafting, editing and reviewing. Y.X and B.Y.: contributed to the manuscript reviewing and editing. Y.X., P.X., and C.R.: contributed to the manuscript reviewing. All authors read and approved of the final manuscript.

\section{References}

1 Ankawi G, Neri M, Zhang J, Breglia A, Ricci Z, Ronco C. Extracorporeal techniques for the treatment of critically ill patients with sepsis beyond conventional blood purification therapy: the promises and the pitfalls. Crit Care. 2018 Oct;22(1):262.

2 Datzmann T, Träger K. Extracorporeal membrane oxygenation and cytokine adsorption. J Thorac Dis. 2018 Mar;10(Suppl 5):S653-60.

3 Eichhorn T, Rauscher S, Hammer C, Gröger M, Fischer MB, Weber V. Polystyrene-Divinylbenzene-Based Adsorbents Reduce Endothelial Activation and Monocyte Adhesion Under Septic Conditions in a Pore Size-Dependent Manner. Inflammation. 2016 Oct; 39(5):1737-46.
4 Gruda MC, Ruggeberg KG, O’Sullivan P, Guliashvili T, Scheirer AR, Golobish TD, et al. Broad adsorption of sepsis-related PAMP and DAMP molecules, mycotoxins, and cytokines from whole blood using CytoSorb ${ }^{\circledR}$ sorbent porous polymer beads. PLoS One. 2018 Jan; 13(1):e0191676.

5 Friesecke S, Stecher SS, Gross S, Felix SB, Nierhaus A. Extracorporeal cytokine elimination as rescue therapy in refractory septic shock: a prospective single-center study. J Artif Organs. 2017 Sep;20(3):252-9.

6 Kogelmann K, Jarczak D, Scheller M, Drüner M. Hemoadsorption by CytoSorb in septic patients: a case series. Crit Care. 2017 Mar; 21(1):74.
7 Schädler D, Porzelius C, Jörres A, Marx G, Meier-Hellmann A, Putensen C, etal. A multicenter randomized controlled study of an extracorporeal cytokine hemoadsorption device in septic patients. Crit Care. 2013;17(Suppl 2):P62.

8 Schädler D, Pausch C, Heise D, Meier-Hellmann A, Brederlau J, Weiler N, et al. The effect of a novel extracorporeal cytokine hemoadsorption device on IL-6 elimination in septic patients: A randomized controlled trial. PLoS One. 2017 Oct;12(10):e0187015.

9 Träger K, Fritzler D, Fischer G, Schröder J, Skrabal C, Liebold A, et al. Treatment of post-cardiopulmonary bypass SIRS by hemoadsorption: a case series. Int J Artif Organs. 2016 May; 39(3):141-6. 
10 Bernardi MH, Rinoesl H, Dragosits K, Ristl R, Hoffelner F, Opfermann P, et al. Effect of hemoadsorption during cardiopulmonary bypass surgery - a blinded, randomized, controlled pilot study using a novel adsorbent. Crit Care. 2016 Apr;20(1):96.

11 Träger K, Skrabal C, Fischer G, Datzmann T, Schroeder J, Fritzler D, et al. Hemoadsorption treatment of patients with acute infective endocarditis during surgery with cardiopulmonary bypass - a case series. Int J Artif Organs. 2017 May;40(5):240-9.

12 Calabrò MG, Febres D, Recca G, Lembo R, Fominskiy E, Scandroglio AM, et al. Blood Purification With CytoSorb in Critically Ill Patients: Single-Center Preliminary Experience. Artif Organs. 2019 Feb;43(2):189-194.

13 Nemeth E, Kovacs E, Racz K, Soltesz A, Szigeti S, Kiss N, et al. Impact of intraoperative cytokine adsorption on outcome of patients undergoing orthotopic heart transplantation-an observational study. Clin Transplant. 2018 Apr;32(4):e13211.

14 Kellum JA, Venkataraman R, Powner D, Elder M, Hergenroeder G, Carter M. Feasibility study of cytokine removal by hemoadsorption in brain-dead humans. Crit Care Med. 2008 Jan;36(1):268-72.

15 Hartmann J, Harm S. Removal of bile acids by extracorporeal therapies: an in vitro study. Int J Artif Organs. 2017 Sep;41(1):52-57.

16 Koertge A, Wasserkort R, Wild T, Mitzner S. Extracorporeal Hemoperfusion as a Potential Therapeutic Option for Critical Accumulation of Rivaroxaban. Blood Purif. 2018;45(13):126-8.

17 Angheloiu GO, Gugiu GB, Ruse C, Pandey R, Dasari RR, Whatling C. Ticagrelor Removal From Human Blood. JACC Basic Transl Sci. 2017 Apr;2(2):135-45.

18 Angheloiu GO, Hänscheid H, Wen X, Capponi V, Anderson WD, Kellum JA. Experimental first-pass method for testing and comparing sorbent polymers used in the clearance of iodine contrast materials. Blood Purif. 2012;34(1):34-9.

19 Reiter K, Bordoni V, Dall'Olio G, Ricatti MG, Soli M, Ruperti S, et al. In vitro removal of therapeutic drugs with a novel adsorbent system. Blood Purif. 2002;20(4):380-8.
20 Friesecke S, Träger K, Schittek GA, Molnar Z, Bach F, Kogelmann K, et al. International registry on the use of the CytoSorb ${ }^{\circledR}$ adsorber in ICU patients: Study protocol and preliminary results. Med Klin Intensivmed Notfmed. 2017 Sep 4.

21 Winchester JF, Silberzweig J, Ronco C, Kuntsevich V, Levine D, Parker T, et al. Sorbents in acute renal failure and end-stage renal disease: middle molecule and cytokine removal. Blood Purif. 2004;22(1):73-7.

22 Malard B, Lambert C, Kellum JA. In vitro comparison of the adsorption of inflammatory mediators by blood purification devices. Intensive Care Med Exp. 2018 May;6(1): 12.

23 Yakoub-Agha I, Moreau AS, Ahmad I, Borel C, Hadhoum N, Masouridi-Levrat S, et al. [Management of cytokine release syndrome in adult and pediatric patients undergoing CAR-T cell therapy for hematological malignancies: Recommendation of the French Society of Bone Marrow and cellular Therapy (SFGM-TC)]. Bull Cancer. 2019 Jan;106 1S: S102-9. 